\title{
Sazonalidade dos ductos secretores e óleo essencial de Foeniculum vulgare var. vulgare Mill. (Apiaceae)
}

\author{
L.A. Sousa ${ }^{1 *}$, J.C.R. Albuquerque ${ }^{2}$, M.N. Leite ${ }^{1}$, M.B. Stefanini ${ }^{3}$ \\ ${ }^{1}$ Departamento Farmacêutico, Faculdade de Farmácia e Bioquímica, \\ Universidade Federal de Juiz de Fora, Martelos, 36016-970, Juiz de Fora, MG, Brasil, \\ ${ }^{2}$ Central Analítica, Farmanguinhos - FIOCRUZ, 21041-250, Rio de Janeiro, RJ, Brasil, \\ ${ }^{3}$ Departamento de Horticultura, Faculdade de Ciências Agronômicas de Botucatu, UNESP, \\ 18603-970, Botucatu, SP, Brasil
}

\begin{abstract}
RESUMO: Este trabalho teve como objetivo analisar os ductos secretores e o óleo essencial das folhas de Foeniculum vulgare em diferentes épocas do ano. Para esta finalidade, foram realizados estudos de caracterização anatômica, bem como anatomia comparada dos ductos secretores e testes histoquímicos das folhas. O óleo essencial foi obtido de folhas e frutos, por hidrodestilação em aparelho de Clevenger e analisados quantitativamente e qualitativamente por cromatografia em fase gasosa acoplada ao espectrômetro de massa, realizando-se análises seguidas de três réplicas para folhas coletadas durante o inverno e primavera, e frutos no verão. Os resultados encontrados para os ductos secretores de óleo corresponderam à redução do teor de óleo essencial nas folhas coletadas no final da primavera. O componente majoritário do óleo essencial de folhas e frutos foi o trans-anetol, durante todas as estações do ano. Portanto, evidenciou-se que os ductos secretores e teor de óleo essencial estão relacionados, bem como os constituintes químicos também estão sujeitos a sazonalidade, conforme o estágio fenológico da planta.
\end{abstract}

Unitermos: Foeniculum vulgare, sazonalidade, ductos secretores, óleo essencial.

\begin{abstract}
Seasonality of the secretory ducts and essential oil of Foeniculum vulgare var. vulgare Mill. (Apiaceae)”. This work aimed to analyze the secretory ducts and the essential oil of the leaves of Foeniculum vulgare in different periods of the year. For this purpose, the anatomic characterization, and histochemical tests of the leaves were performed as well as the comparative anatomy of the secretory ducts. The essential oil was obtained from the leaves and fruits by hidrodistillation in a Clevenger-type apparatus and analyzed by gas chromatography coupled to a mass spectrometer, each analysis was repeated three times for leaves collected during the winter and spring, and for fruits collected in the Summer. The results obtained for the secretory ducts, corresponded to the yield reduction of essential oil in the leaves collected in the end of the spring. The major substance of the essential oil of the leaves and fruits, in all seasons of the year was trans-anetol. Therefore, it was evidenced that the secretory ducts and yield of essential oils are related, and also that the substances are subject to the seasonality, according to the phenologic stage of the plant.
\end{abstract}

Keywords: Foeniculum vulgare, seasonality, secretory ducts, essential oil.

\section{INTRODUÇÃO}

Foeniculum vulgare Mill. é uma planta originária da Europa, ocorrendo com freqüência em Portugal e Espanha, mas sendo cultivada em diversos países, principalmente, na região do mediterrâneo, Ásia, norte da África e América do Sul (Costa, 1994; Czygan et al., 1994). Ela foi introduzida no sul do Brasil pelos colonos no século XVI (Pio Correia, 1984) e, atualmente, existem grandes culturas de funcho nos estados do Rio Grande do Sul, Santa Catarina e Paraná (Cruz, 1964; Mathias et al., 1972).

Segundo Muckensturm et al. (1997), a espécie $F$. vulgare pode ser dividida em duas subespécies, piperitum e vulgare, sendo que a subespécie vulgare é reconhecida por quatro variedades e uma destas variedades (variedade vulgare) é reconhecida por três quimiotipos, estragol, estragol/anetol e anetol.

$\mathrm{Na}$ literatura científica consultada, foram encontrados diferentes trabalhos sobre os aspectos químicos, merecendo destaque para aqueles da autoria de Sur et al., 1991; Muckensturm et al., 1997; Figueiredo et al., 2000; Bilia et al., 2000; e Piccaglia; Marotti, 2001.

Em relação aos aspectos anatômicos foliares do funcho, não foram encontrados trabalhos específicos, mas Judd et al. (1999), mencionaram que os ductos secretores de óleos voláteis são utilizados como marcadores morfológicos em Apiaceae e que os mesmos ainda são 
utilizados em relações filogenéticas.

De acordo com Ricklefs (1996), alguns padrões globais de temperatura e umidade, resultantes da absorção solar local e da redistribuição da energia térmica, estão associados com cada tipo de planta e com sua prosperidade a uma estreita faixa de condições ambientais. Portanto, devido a aclimatação do funcho no Brasil, que apresenta climas tropicais e subtropicais, ou seja, diferentes daqueles da região de origem da planta (mediterrâneo), as estações do ano refletem principalmente nos ciclos anuais de temperatura e outros tipos de fatores abióticos, gerando assim uma sazonalidade que influencia na vida da planta.

Desta forma, este trabalho objetivou relacionar a sazonalidade dos ductos secretores (ocorrência) e teor do óleo essencial de folhas de Foeniculum vulgare, com a finalidade de contribuir para o melhor conhecimento botânico da espécie, bem como maximizar a utilização do óleo essencial, uma vez que a espécie apresenta compostos químicos com ampla utilização industrial e aplicações medicinais.

\section{MATERIAL E MÉTODOS}

Foeniculum vulgare Mill. (Apiaceae), foi cultivado na Estação Experimental de Botânica (EEB/ UFJF); a identificação botânica foi realizada no Herbário Leopoldo Krieger (CESJ) do Instituto de Ciências Biológicas da UFJF, onde se encontra depositado a exsicata de $n^{0}$ 30649. Curadora responsável pela identificação: Professora Farmacêutica Selma Moraes Sarmento Verardo.

Os estudos foram desenvolvidos no campus da UFJF, situada a uma altitude média de 678 metros (latitude $21^{\circ} 46^{\prime}$ S; longitude $43^{\circ} 21^{\prime}$ W) na Zona da Mata Mineira, Minas Gerais - posição geográfica do município, clima tropical de altitude, temperatura média de $19,3^{\circ} \mathrm{C}$ e umidade relativa do ar 79,8\% (Yacoub, 1998).

O experimento foi conduzido em dois canteiros, cada qual com 50 plantas, que seguiu os padrões agroecológicos (Primavesi, 1997). Empregou-se adubação orgânica à base de esterco bovino e utilizou-se inseticida natural (fumo de rolo/sabão de coco), a cada 20 dias, como um controle alternativo de parasitas da planta (afídeos), segundo Saito; Lucchini (1998). No canteiro controle foi aplicado inseticida natural com a finalidade de controlar a proliferação dos parasitas, com espaçamento de $0,8 \mathrm{~m}$ na linha e $0,6 \mathrm{~m}$ na entre linha para as plantas, enquanto que no canteiro não controle (testemunha) não houve aplicação de inseticidas naturais e espaçamento entre as plantas.

Após o desenvolvimento das plantas, ao longo de seis meses, coletou-se as partes aéreas (folhas), utilizando-se a região mediana como área amostral, para a elaboração de estudos sobre anatomia vegetal descritiva das estruturas internas da folha, anatomia comparada com relação à presença de ductos secretores de óleo, em diferentes épocas de coleta (fenofase vegetativa e reprodutiva/floração - final do inverno e primavera, respectivamente) e testes histoquímicos que foram realizados no Departamento de Botânica da UFJF (Castro; Machado, 2003; Menezes et al., 2003)

O procedimento adotado na caracterização anatômica foi o seguinte: acondicionamento em FAA $50 \%$, cortes transversais manuais com auxílio de isopor, clareamento em hipoclorito de sódio $50 \%$, desidratação etanol 50\%, coloração em azul de astra e safranina 1\%, montagem de lâminas semi-permanentes e realização de fotografias em microscópio óptico (Kraus; Arduim, 1997)

Para a anatomia comparada de ductos secretores procedeu-se apenas as duas primeiras etapas citadas anteriormente (acondicionamento em FAA 50\% e cortes transversais manuais com auxílio de isopor). Foi padronizado que os cortes comparativos entre as fenofases seriam referentes à região mediana dos segmentos foliares (pecíolo, raques primária e secundária, e foliólulo), seguida da contagem de ductos secretores no microscópio óptico, analisando toda a região do parênquima fundamental.

Nos testes histoquímicos, foram utilizados cloreto férrico a $3 \%$ e sulfato ferroso a $4 \%$ em formalina para evidenciar a presença de compostos fenólicos; lugol para evidenciar a presença de amido; SUDAM III para evidenciar a presença de substâncias lipofílicas (Kraus; Arduim, 1997) e DMACA para evidenciar a presença de flavonóides (Feucht et al., 1986).

Na análise do óleo essencial, utilizou-se amostras de $100 \mathrm{~g}$ a partir de três réplicas de folhas (final do inverno e primavera) e frutos (final do verão) dos dois canteiros da EEB.

Após a obtenção da matéria seca (secagem a $37{ }^{\circ} \mathrm{C}-48$ horas) em estufa comum, folhas e frutos foram submetidos a testes químicos (hidrodestilação em aparelho de Clevenger e identificação de bioativos) para avaliação do óleo essencial, de forma quantitativa e qualitativa.

A extração do óleo essencial foi realizada no Laboratório de Farmacognosia da Faculdade de Farmácia e Bioquímica da UFJF, adotando-se o método de hidrodestilação em aparelho de Clevenger, por 4 horas, onde foram utilizados um litro de $\mathrm{H}_{2} \mathrm{O}$. Os resultados de teor do óleo essencial foram expressos em porcentagem (\%) de óleo essencial em relação à matéria seca. Também foram levadas em consideração as características organolépticas (cor e odor) do óleo essencial de folhas e frutos.

Para a análise dos óleos essenciais, as amostras foram submetidas à cromatografia em fase gasosa acoplada ao espectrômetro de massa (CG-EM) na Central Analítica - Far-Manguinhos/FIOCRUZ/RJ.

Na CG-EM, as amostras foram diluídas em clorofórmio e, posteriormente, realizou-se as análises. O aparelho usado foi o modelo HP 6890 SERIES/Mass Selective Detector (Hewlett Packard), usando 30m x 
0,25mm HP5 (meio polar) e coluna capilar $(0,25 \mu \mathrm{m})$, sendo a amostra injetada por partição. A temperatura foi programada da seguinte forma: $50{ }^{\circ} \mathrm{C}$ (5 min.), de 50 $300{ }^{\circ} \mathrm{C}$ com um aumento de $2{ }^{\circ} \mathrm{C}$ por minuto até 300 ${ }^{\circ} \mathrm{C}$ (130 minutos). As áreas e porcentagens referentes a cada constituinte do óleo foram obtidas em um software acoplado ao CG-EM e a identificação feita por comparação dos espectros com os padrões da biblioteca interna de dados (CAS- Chemical Abstracts) e dos tempos de retenção.

\section{RESULTADOS E DISCUSSÃO}

\section{Caracterização anatômica}

Descrição anatômica - caracteres gerais: Em todas as regiões da folha, exceto no foliólulo, a epiderme (seção transversal) é pluriestratificada constituídas por duas camadas de células de seção transversal retangular. Em todas as regiões da folha, a epiderme é recoberta por uma cutícula fina (que geralmente é perdida durante os processos de clareamento, desidratação e/ou coloração). Abaixo da iderme encontra-se o parênquima paliçádico formado por duas ou três camadas de células de seção transversal elípitca ou arredondada, para todas as regiões da folha (Figura 1).

$\mathrm{Na}$ bainha, o parênquima paliçádico ocorre apenas na face dorsal. No foliólulo, abaixo da epiderme encontra-se o parênquima paliçádico (Figura 1).

Abaixo do parênquima paliçádico na bainha, pecíolo, raque $1^{\mathrm{a}}$ e $2^{\mathrm{a}}$ e no foliólulo ocorre o parênquima medular com células de seção transversal poliédrica, geralmente formando um hexágono e/ou heptágono (Figura 1).

Os tecidos vasculares, estão distribuídos de forma circular ao longo da circunferência em torno da folha (pecíolo, raque $1^{\mathrm{a}}$ e $2^{\mathrm{a}}$ e foliólulo), exceto na bainha, onde encontra-se adjacente ao parênquima paliçádico, na face dorsal da folha (Figura 1).

No parênquima medular, ainda pode-se encontrar ductos secretores de óleos dispersos nas proximidades dos tecidos vasculares e ductos maiores na região entre o floema e nos feixes de fibras esclerênquimáticas (Figura $1)$.

Os ductos secretores de óleo encontram-se envoltos por células epiteliais do parênquima, que variam de 5 a 7 células, e ocorrem em maior número no pecíolo foliar, e progressivamente, em menor número nos demais segmentos foliares.

Conforme Carmello et al. (1995), os ductos secretores de Lithraea molleoides estão restritos ao floema no caule, mas neste estudo verificou-se que os mesmos também encontram-se dispersos pelo parênquima fundamental (medular) das folhas. Eles relataram também que, a partir de ensaios histoquímicos, evidenciou-se que os ductos secretores, além de conterem compostos fenólicos, apresentam lipídios e polissacarídeos.
De acordo com Judd et al. (1999), os ductos secretores de óleos são utilizados para caracterizar a família Apiaceae e, conseqüentemente, indicar apomorfias com a família Pittosporaceae.

Segundo a anatomia comparada dos ductos secretores das folhas nas diferentes fenofases, evidenciouse que a presença de ductos secretores de óleo nas folhas de $F$. vulgare, coletadas durante a fenofase vegetativa (final do inverno), ocorreu em média de 74, 51, 20 e 3, no pecíolo, raques primária, secundária e foliólulo, respectivamente.

Durante a fenofase reprodutiva (final da primavera), que correspondeu à floração, observouse que os ductos secretores diminuíram, ocorrendo em média de 47, 27, 9 e 3, nas mesmas regiões da folha, justificando indiretamente a redução no teor de óleo essencial durante o período quente úmido, referente à esta época de colheita.

Sugere-se também que a diminuição dos ductos secretores se deve ao fato do desvio de fotoassimilados da fonte para dreno, que corresponde ao estágio de floração.

Deve-se considerar que nos ductos secretores pode-se encontrar outros metabólitos e que esses não estão restritos apenas aos mesmos (Carmello et al., 1995). Por isto, este trabalho relacionou a redução indireta do óleo essencial com a diminuição de ductos secretores nas folhas, ou seja, a redução dos ductos secretores pode estar relacionada à redução no teor de óleo essencial, porém a sua redução também está associada aos estágios fenológicos e estado fisiológico.

Os resultados obtidos, nos testes histoquímicos, realizados com as folhas de F. vulgare var. vulgare, encontram-se na Tabela 1 e Figura 1.

\section{Caracterização do óleo essencial}

O teor de óleo essencial variou de 2,4 a 2,6 \%, em frutos e de 0,8 a $1,6 \%$, em folhas, destacando-se que os maiores rendimentos foram encontrados nos frutos.

Entre as características organolépticas, evidenciou-se que a cor do óleo nas folhas (amarelo a transparente) foi diferente do fruto (esbranquiçado a transparente), porém o odor foi adocicado (anisado) em ambas as amostras.

As folhas apresentaram uma variação com relação ao teor de óleo em diferentes épocas, sendo possível verificar uma tendência à diminuição no teor do óleo entre as diferentes estações climáticas (final do inverno - 1,0 e 1,6\% e final da primavera - 0,8 e 1,4\%). Nas folhas do canteiro controle, observou-se ainda um maior teor de óleo em relação ao não controle, isto possivelmente deve-se aos tratos culturais adotados, como o cultivo agroecológico (Tabela 2).

Foi possível observar uma variação considerável no teor de óleo essencial das folhas, em relação a fenofases vegetativa e reprodutiva da planta, uma vez

Rev. Bras. Farmacogn. Braz J. Pharmacogn 15(2):abr/jun. 2005 

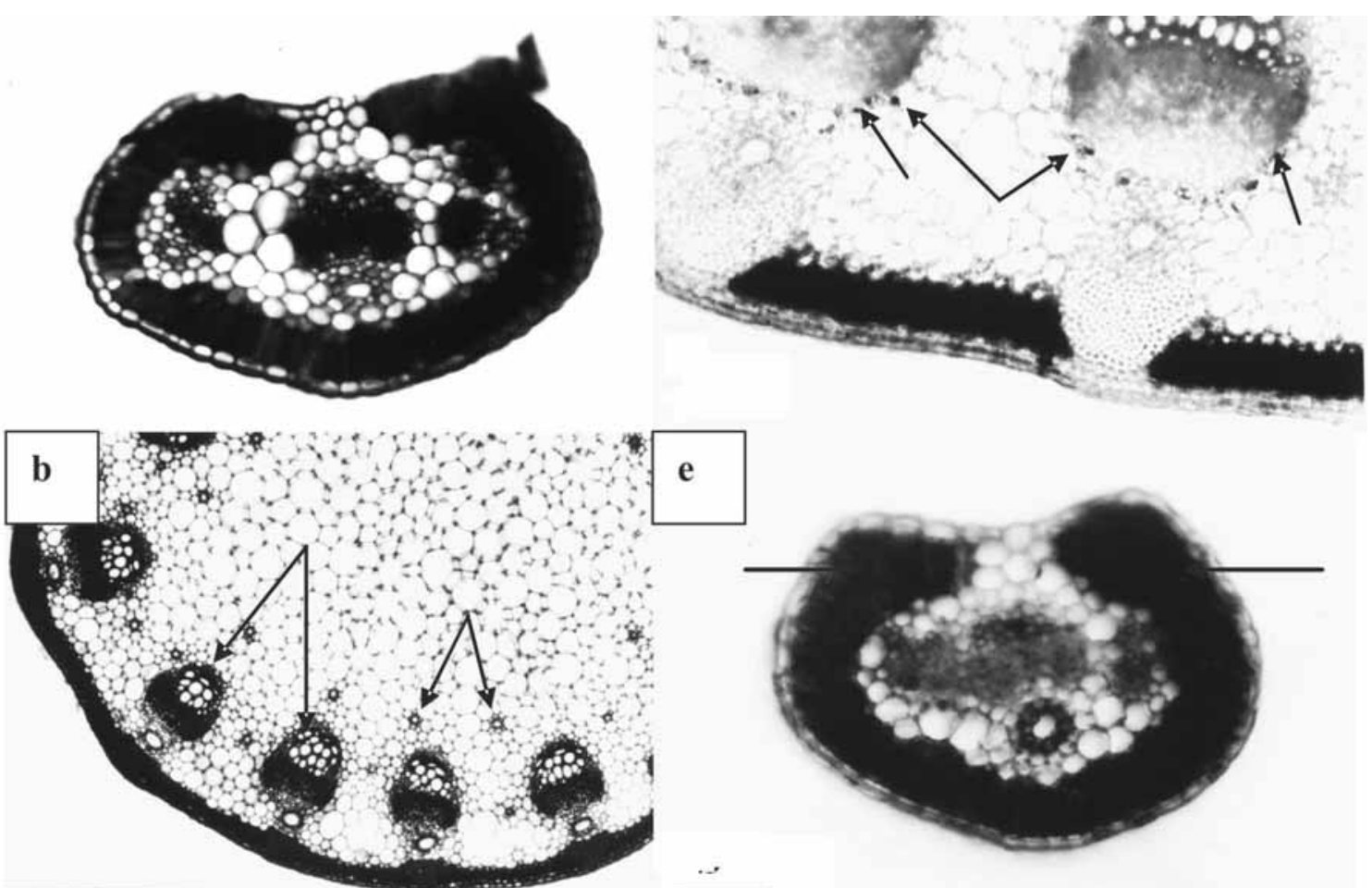

e
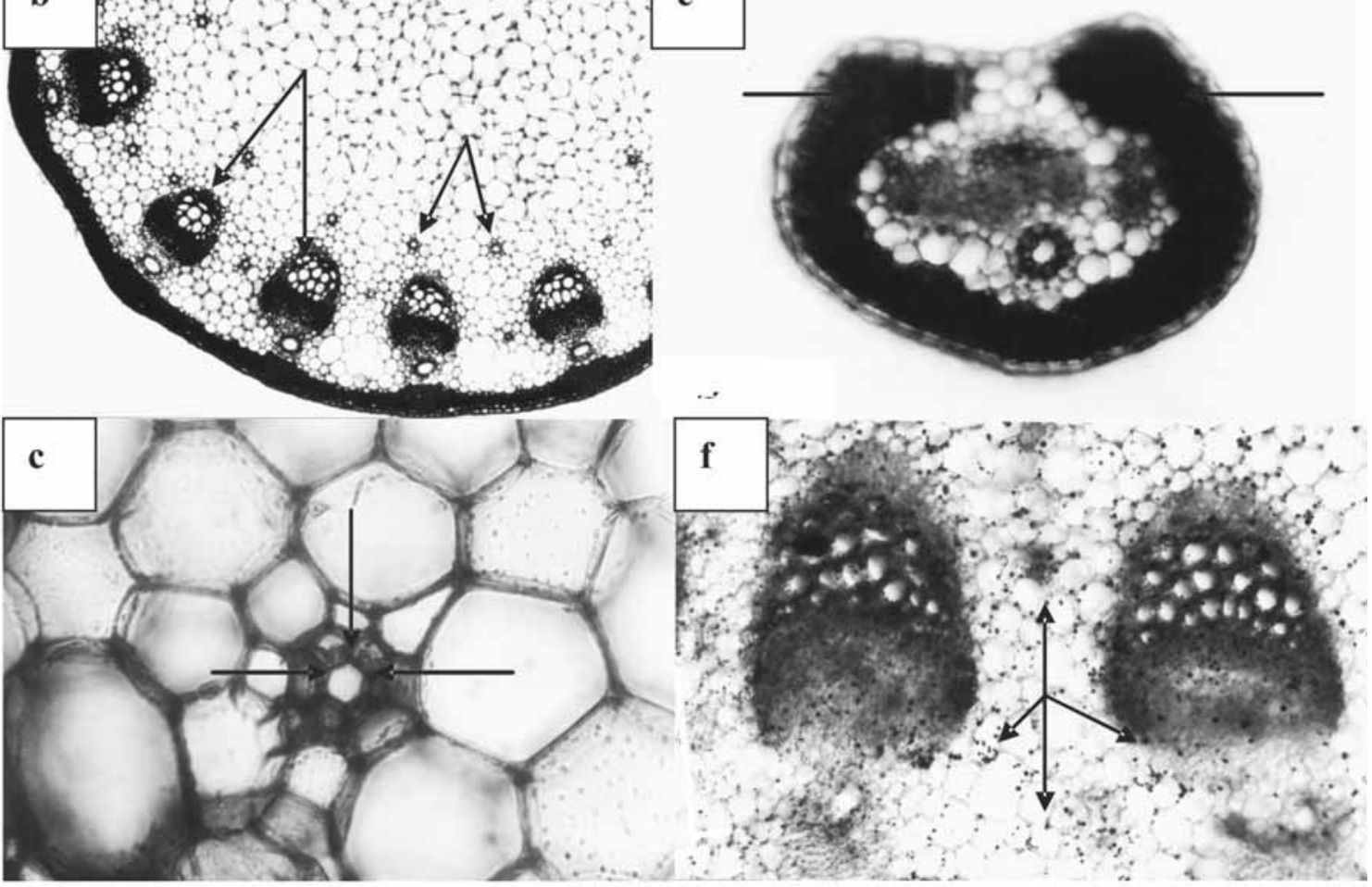

Figura 1. Anatomia e histoquímica das folhas de F. vulgare var. vulgare (Apiaceae).

a) Corte transversal da folha: vista geral do foliólulo (escala $60 \mu \mathrm{m}$ ); b) Corte transversal da folha: raque primária, região do parênquima fundamental, mostrando o feixe vascular e os ductos secretores ao seu redor - setas (escala $25 \mu \mathrm{m}$ ); c) Ducto secretor de óleo essencial, encontrado na região do parênquima fundamental - setas (escala $60 \mu \mathrm{m}$ ). d) Amido evidenciado por grânulos violáceos nas proximidades da bainha amilífera - setas, reagente lugol (Região do pecíolo; aumento 20x; escala: $40 \mu \mathrm{m}$ ); e) Fenólicos evidenciados por pigmentação escura (preto), na região do parênquima clorofiliano e células ao redor do ducto secretor - setas, reagente sulfato ferroso 4\%. (Foliólulo; aumento 20x; escala: $40 \mu \mathrm{m}$ ); f) Substâncias lipófilas evidenciados por grânulos vermelhos, dispersos pelo parênquima fundamental - setas, reagente Sudam III (Raque primária; aumento 20x; escala: $40 \mu \mathrm{m}$ ).

que no final da primavera as folhas produzem um teor de óleo menor do que o encontrado no final do inverno e em relação àquele encontrado nos frutos durante o verão, que pode ser explicado pelo início da fenofase reprodutiva da planta (início do período de floração) e pela redução dos ductos secretores, conforme evidenciado neste estudo. Porém também devemos considerar que outros tecidos, células e sinalizadores moleculares podem influenciar nas rotas fisiológicas do metabolismo secundário.

Os frutos coletados no final do verão, apresentaram os maiores valores no teor de óleo essencial, sendo que o canteiro não controle, apresentou um maior teor de óleo (2,6\%), quando comparado ao controle $(2,4 \%)$ (Tabela 2).

Segundo os procedimentos agronômicos adotados, verificamos que no canteiro controle os teores de óleo essencial para as folhas foram superiores em relação ao canteiro não controle, mas para os frutos observou-se o contrário, demonstrando-se que a utilização de padronização do espaçamento, o uso de inseticidas naturais e cultivo agroecológico foram indiferentes, porém são necessários a utilização de espaçamentos entre 
Tabela 1. Resultados dos testes histoquímicos realizados com folhas de Foeniculum vulgare var. vulgare (Apiaceae).

\begin{tabular}{llll}
\hline Testes & Reagente & Folha & Tecido evidenciado \\
\hline Amido & Lugol & + & parênquimático (associado ao tecido vascular) \\
Fenólicos & Cloreto férrico 3\% & - & parênquimático \\
Flavonóides & DMACA & - & parênquimático \\
Fenólicos & Sulfato ferroso 4\% & +++ & dérmico, parênquimático* e vascular \\
S. lipofílas & Sudam III & +++ & dérmico, parênquimático* e vascular \\
\hline
\end{tabular}

(-) não evidenciado; (+) evidenciado; (+++) evidenciado em alto índice;

S.lipófilas: substâncias lipofílicas * Ductos secretores.

as plantas, pois proporcionam maior uniformidade de desenvolvimento para a cultura.

De acordo com Larcher (2000), os metabólitos secundários podem estar sujeitos a variações quando relacionados ao estágio do desenvolvimento, bem como as estações do ano, conforme as relações obtidas neste estudo.

O horário de colheita das folhas e frutos, foram às 12:00, durante todo o estudo, sendo um aspecto importante com relação a obtenção de teores de óleo essencial satisfatórios. Conforme citado por Sharapin et al., (2000), as plantas produtoras de óleo essencial, geralmente, alcançam altos teores ao redor de meiodia, comprovando a eficácia obtida na padronização do horário de colheita do funcho neste trabalho, porém a concentração dos compostos podem oscilar entre poucas horas e conforme a estação do ano (Larcher, 2000), para esta planta meio-dia foi um horário satisfatório, mas não devemos generalizar para outras espécies e variedades.

No espectro de CG-EM, foi possível verificar a presença de compostos no óleo essencial das folhas e dos frutos (Tabela 3), havendo variação na composição química quando comparado parcialmente (devido as diferenças metodológicas) com os resultados encontrados na literatura (Muckensturm et al., 1997; Piccaglia;
Marotti, 2001).

Entre todos os compostos de F. vulgare, o transanetol foi o mais representativo tanto para as folhas como para o fruto, confirmando assim o uso medicinal da planta, bem como outros compostos de destaque presentes nas folhas coletadas no final do inverno, limoneno, $\alpha$ felandreno e $\alpha$-pineno (Tabela 3 ), respectivamente.

As oscilações observadas na concentração dos compostos variaram entre as estações do ano, considerando-se como referência a padronização do horário de colheita, porém esta variação reflete nas diferentes estações (Larcher, 2000).

A composição química obtida neste trabalho, assemelha-se àquela obtida por Muckensturm et al. (1997), sendo possível descrever que o funcho (F. vulgare), segundo o uso de marcadores micromoleculares, como pertencente a subespécie vulgare, variedade vulgare, considerando, inclusive as diferenças metodológicas no processo de extração e técnicas cromatográficas. Porém, observou-se que não houve a produção de compostos como o estragol, fenchona, sabineno e 10-nonacosanona nas folhas e estragol, fenchona, limoneno, sabineno, terpinoleno, $\beta$-felandreno, $\alpha$-pineno, $\gamma$-terpineno e 10-nonacosanona nos frutos conforme citado por Muckensturm et al. (1997).

Tabela 2. Teores de óleo essencial (\%) das folhas e frutos de Foeniculum vulgare var. vulgare, coletadas em diferentes estações do ano, obtidos por hidrodestilação a partir de três réplicas com 100g de matéria seca por canteiro de cultivo.

\begin{tabular}{lccc}
\hline \multicolumn{2}{c}{ Estrutura e época } & & \\
\hline$\%$ Óleo essencial & Folhas & Folhas & Frutos \\
& Inverno & Primavera & Verão \\
\hline Canteiro controle & 1,6 & 1,4 & 2,4 \\
Canteiro não controle & 1,0 & 0,8 & 2,6 \\
\hline Média & 1,3 & 1,1 & 2,5 \\
\hline
\end{tabular}

Canteiro controle: padrão agroecológico; e canteiro não controle: testemunha. 
Tabela 3. Composição química dos óleos essenciais de folhas e frutos de Foeniculum vulgare var. vulgare, obtidos em diferentes épocas do ano, análise realizada por CG-EM.

\begin{tabular}{|c|c|c|c|}
\hline \multicolumn{4}{|c|}{ Estrutura e Época } \\
\hline Composição química & Folhas Inverno & Folhas Primavera & Frutos Verão \\
\hline Acetato de $\alpha$-fenchila & $3,35 \%(21,81)^{*}$ & - & - \\
\hline$\alpha$-Felandreno & $7,14 \%(8,8) *$ & - & $0,32 \%(12,72)^{*}$ \\
\hline$\beta$-Felandreno & - & $2,42 \%(10,30)^{*}$ & \\
\hline Isopreno-2-metil-1,3 butadieno & - & - & $1,28 \%(13,74) *$ \\
\hline Limoneno & $13,53 \%(10,12)^{*}$ & - & - \\
\hline 2,6-Nonadienol & & $4,28 \%(11,07)^{*}$ & - \\
\hline$\alpha$-Pineno & $3,5 \%(5,61)^{*}$ & $4,02 \%(7,01)^{*}$ & - \\
\hline trans-Anetol & $70,87 \%(27,16)^{*}$ & $80,65 \%(14,68) *$ & $94,16 \%(27,99)^{*}$ \\
\hline
\end{tabular}

* Tempo de retenção em minutos.

Desta forma, sugere-se que esta diferença na composição química de $F$. vulgare em relação aos outros quimiotipos da variedade vulgare, seja devido a um contraste ambiental, uma vez que diversos fatores, sejam eles, técnicos, antrópicos, abióticos e bióticos, venham influenciar na produção destes metabólitos secundários.

De acordo com Futuyama (1997), tal variação na composição química, pode estar associada ao ambiente ecológico, que inclui fatores bióticos e abióticos. Os metabólitos especiais enquadram-se neste processo, pois conforme a adaptabilidade de uma planta a um certo ambiente, ela pode investir ou não na produção de substância bioativas (Gottlieb et al., 1996).

Conforme citado por Mann (1987), estes metabólitos secundários fazem parte de um processo evolutivo, resultante de modificações ambientais, climáticas, geológicas, relações simbióticas com outros organismos da fauna e flora locais que promovem interações químicas e coadaptações de plantas, herbívoros e microorganismos.

\section{CONCLUSÕES}

Os componentes do óleo essencial de $F$. vulgare var. vulgare variaram quantitativamente $\mathrm{e}$ qualitativamente de acordo com a fenologia e época do ano em que se coletou a planta. O composto majoritário encontrado tanto nas folhas como nos frutos foi o transanetol, destacando, que o mesmo composto comportou-se de forma diferente em relação ao teor no óleo das folhas entre o final do inverno e da primavera. Destaca-se ainda que as folhas coletadas no final do inverno, apresentaram uma maior composição em constituintes químicos.

Portanto, de acordo com os resultados obtidos no presente trabalho verifica-se que não apenas o ambiente pode ter grande influência na sazonalidade dos ductos secretores e do óleo essencial mas que é preciso considerálo como um componente importante no processo biossintético, visto que tais marcadores morfológicos e micromoleculares são fundamentais para o entendimento dos aspectos biológicos, agronômicos e químicos de espécies com interesse industrial e medicinal.

\section{AGRADECIMENTOS}

Os autores agradecem à Fundação de Amparo à Pesquisa do Estado de Minas Gerais (FAPEMIG) pela concessão de uma bolsa de iniciação científica para o primeiro autor.

\section{REFERÊNCIAS}

Bilia AR, Fumarola M, Gallori S, Mazzi G, Vincier I 2000. Identification by HPLC-DAD and HPLC-MS analysis and quantification of constituents of fennel teas and decoctions. J Agric Food Chem 48: 4734-4738.

Castro MM, Machado SR 2003. Células e tecidos secretores. In: Appezzato-da-Glória B, Carmello-Guerreiro SM Anatomia vegetal. Viçosa: UFV. 307-325p.

Carmello SM, Machado SR, Grergório EA 1995. Ultrastructural aspects of the secretory duct development in Lithraea molleoides (Vell.) Engl. (Anacardiaceae). Rev Bras Bot 18: 95-103.

Costa AF 1994. Farmacognosia. 4 ed., Lisboa: Fundação Calouste Gubenkian.

Cruz GL 1964. Dicionário de plantas úteis do Brasil. 4 ed. Rio de Janeiro.

Czygan FC, Frohne D, Höltzel C, Nagell A, Pfänder HJ, Willuhn G, Buff W 1994. Herbal Drugs and Phytopharmaceuticals. Ed. Norman Grainger Bisset, Stuttgart, Germany.

Feucht W, Schimid PPS, Martins RP 1986. Distribution of 
flavonols in meristematic and mature tissues of Prunnus evium shoots. J Plant Physiol 125: 1-8.

Figueiredo RO, Ming LC, Stefanini MB 2000. Teor de óleo essencial em sementes de funcho em dois estádios de maturação. Hortic Bras 18: 922-923.

Futuyama DJ 1997. Biologia evolutiva. 2 ed. Ribeirão Preto: Sociedade Brasileira de Genética/CNPq.

Gottlieb OR, Kaplan MAC, Borin MRMB 1996. Biodiversidade: um enfoque químico-biológico. Rio de Janeiro: Editora UFRJ.

Judd WS, Campbell CS, Kellogg EA, Stevens PF 1999. Plant systematics: a phylogenetic approach. Sinauer Associates, Inc. Publishers. Sunderland, Massachusetts U.S.A.

Kraus JE, Arduim M 1997. Manual básico de métodos em morfologia vegetal. Ed. Universidade Federal Rural do Rio de Janeiro, Seropédica.

Larcher W 2000. Ecofisiologia vegetal. São Carlos: Editora Rima.

Mann J 1987. Secondary metabolism. $2^{\text {nd }}$. ed. Oxford: Oxford Science Publications.

Mathias ME, Constante L, Araujo D 1972. Flora ilustrada Catarinense. Publicação patrocinada por: Conselho Nacional de Pesquisas, Instituto Brasileiro de Desenvolvimento Florestal, Herbário "Barbosa Rodrigues”. Fascículo: Umbelíferas, Itajaí.

Menezes NL, Silva DC, Pinna GFA 2003. Folha. In: Appezzatoda-Glória B, Carmello-Guerreiro SM Anatomia vegetal. Viçosa: UFV. 307-325p.

Muckensturm B, Foechterlen D, Reduron JP, Dalton P, Hildenbrand M 1997. Phytochemical and chemotaxonomic studies of Foeniculum vulgare. Biochem Syst Ecol 25: 353-358.

Piccaglia R, Marotti M 2001. Characterization of some Italian types of wild fennel (Foeniculum vulgare Mill.). $J$ Agric Food Chem 49: 239-244.

Pio Correa M 1984. Dicionário de plantas úteis do Brasil e exóticas cultivadas. Rio de Janeiro: Imprensa Nacional, Vol.III, p.369-371.

Primavesi A 1997. Agroecologia: ecosfera, tecnosfera e agricultura. São Paulo: Editora Nobel.

Ricklefs RE 1996. A economia da natureza. Rio de Janeiro: Editora Guanabara Koogan.

Saito ML, Lucchini F 1998. Substâncias obtidas de plantas e a procura por praguicidas eficientes e seguros ao meio ambiente. Jaguariúna: EMBRAPA-CNPMA.

Sharapin N, Rocha LM, Carvalho ES, Lúcio EMRA, Santos ELM, Almeida JML 2000. Fundamentos de tecnologia de produtos fitoterápicos. Santafé de Bogotá: $\mathrm{CAB} /$ CYTED Ministério de Educação e Cultura de Espanha.

Sur SV, Tuljupa FM, Sur LI 1991.Gas chromatographic determination of monoterpenes in essential oil medicinal plants. J Chromatogr 542: 451-458.

Yacoub LBD 1998. Manual do aluno: Universidade Federal de Juiz de Fora. Editora Gráfica: Belo Horizonte. 